\title{
A Escola no Contexto do Campo: vivências à partir do Programa
}

\section{Mais Educação}

\author{
La Escuela en el Contexto del Campo: vivencias a partir del Programa \\ Más Educación
}

The School in the Context of the Field: experiences from the More

Education Program

\author{
Vagner Viera de Souza ${ }^{1}$ \\ Sicero Agostinho Miranda ${ }^{2}$ \\ Elaine Corrêa Pereira ${ }^{3}$
}

\begin{abstract}
Resumo
Este trabalho é um relato das experiências vivenciadas durante o Projeto Mais Educação numa escola do campo situada na cidade de Rio Grande (RS). As escolas do campo em suas concepções e espaços, devem levar em consideração as especificidades dos sujeitos que vivem no campo. Estes sujeitos, assim como as pessoas que habitam as zonas urbanas, possuem seus códigos e simbologias (cultura), as quais devem ser relacionadas com os temas abordados em sala de aula. Ainda é pertinente destacar a importância de espaços educativos bem planejados para a aprendizagem do homem do campo. Como estratégia que vem à somar no trabalho desenvolvido na escola na perspectiva da educação popular, temos o Programa Mais Educação, instituído através da Portaria Interministerial número 17/2007 e pelo Decreto $\mathrm{n}^{\circ}$ 7.083, de 27 de janeiro de 2010, com intuito de integrar as ações do Plano de Desenvolvimento da Educação (PDE), como uma estratégia do Governo para o incentivo à ampliação do tempo na escola juntamente com a organização curricular, na perspectiva da Educação Integral. O mesmo proporciona aos alunos um contraturno com atividades pedagógicas que agregam diversos conhecimentos e saberes à sua formação.
\end{abstract}

Palavras-Chave: Autonomia; Educação do Campo; Educação Integral; Escola do Campo; Mais Educação.

\section{Resumen}

Este trabajo es un relato de las experiencias vivenciadas durante el Proyecto Más Educación en una escuela del campo situada en la ciudad de Rio Grande (RS). Las escuelas del campo en sus concepciones y espacios, deben tener en cuenta las especificidades de los sujetos que viven en el campo. Estos sujetos, así como las personas que habitan las zonas urbanas, poseen sus códigos y simbologías (cultura), las cuales deben ser relacionadas con los temas abordados en el aula. Es importante destacar la importancia de espacios educativos bien planificados para el aprendizaje del hombre del campo. Como estrategia que viene a sumar en el trabajo desarrollado en la escuela en la perspectiva de la educación popular, tenemos el Programa Más Educación, instituido a través de la Portaria Interministerial número 17/2007 y por el Decreto $n{ }^{\circ} 7.083$, de 27 de enero de 2010, con el propósito de integrar las acciones del Plan de Desarrollo de la Educación (PDE), como una estrategia del Gobierno para el incentivo a la ampliación del tiempo en la escuela junto con la organización

\footnotetext{
${ }^{1}$ (Licenciando em Geografia; Universidade Federal do Rio Grande - FURG; Rio Grande, Rio Grande do Sul, Brasil; vagner@vagnersouza.com).

${ }^{2}$ (Mestre em Educação em Ciências; Universidade Federal do Rio Grande - FURG; Rio Grande, Rio Grande do Sul, Brasil; siceromiranda@gmail.com).

${ }^{3}$ (Doutora em Engenharia de Produção; Universidade Federal do Rio Grande - FURG; Rio Grande, Rio Grande do Sul, Brasil; elainepereira@prolic.furg.br).
} 
curricular, en la perspectiva de la Educación Integral. El mismo proporciona a los alumnos un contraturno con actividades pedagógicas que agregan diversos conocimientos y saber a su formación.

Palabras claves: Autonomía; Educación del Campo; Educación Integra; Escuela de Camp; Más Educación.

\begin{abstract}
This work is an account of the experiences lived during the More Education Project in a rural school located in the city of Rio Grande (RS). The schools of the field in their conceptions and spaces, must take into consideration the specificities of the subjects that live in the field. These subjects, as well as the people living in urban areas, have their codes and symbologies (culture), which must be related to the topics addressed in the classroom. It is still pertinent to emphasize the importance of educational spaces well planned for the learning of rural man. As a strategy that comes to add in the work developed in the school in the perspective of popular education, we have the More Education Program, instituted through Interministerial Ordinance number 17/2007 and Decree No. 7,083, of January 27, 2010, with the intention of integrating the actions of the Education Development Plan (PDE), as a strategy of the Government to encourage the expansion of school time together with the curricular organization, from the perspective of Integral Education. It provides the students with a pedagogical activity that brings different knowledge and knowledge to their training.
\end{abstract}

Keywords: Autonomy; Field Education; Integral Education; School of the Field; More Education.

\title{
1. Introdução
}

Estamos vivenciando, nos dias de hoje, diversas mudanças em relação ao nosso modo de pensar, aprender e agir. A escola, enquanto instituição de ensino, é o cerne da educação primária, onde os alunos se deparam com os seus primeiros paradigmas. Para além do espaço urbano, os sujeitos do campo, também enfrentam dificuldades ao longo de sua trajetória escolar. Por mais que o senso comum esqueça da pluralidade encontrada no campo, entre os sujeitos aparentemente com um objetivo comum, os homens e mulheres do campo possuem sonhos particulares e, almejam um futuro próspero, assim como os demais membros da sociedade.

Por suas vez, as escolas do campo precisam elaborar e desenvolver espaços educativos capazes de contribuir na formação dos homens do campo, a partir das concepções de Educação Popular (FREIRE, 1996; BRANDÃO, 2000) do Campo (PALUDO, 2001; CALDART, 2003), conforme Paludo (2001):

A educação do campo é ao mesmo tempo uma inovação e uma ressignificação da educação popular para esse momento histórico, o que possibilita dizer que ela se constitui, dependendo de quem a faz (e formula) como educação Popular do Campo. (p. 263)

Nesta mesma perspectiva Caldart (2003) afirma que,

Não há escolas do campo num campo sem perspectivas, com o povo sem horizontes e buscando sair dele. Por outro lado, também não há como implementar um projeto popular de desenvolvimento do campo sem um projeto de educação, e sem expandir radicalmente a escolarização para todos os povos do campo. E a escola pode ser um 
agente muito importante de formação da consciência das pessoas para a própria necessidade de sua mobilização e organização para lutar por um projeto deste tipo. (p.64)

Através destas concepções, entendemos que a escola deve ser um espaço de multiplicidades, no qual sejam levadas em consideração a pluralidade cultural e as motivações destes contextos (BRANDÃO, 2000) . O presente estudo tem por objetivo discutir sobre as estratégias pedagógicas e o Programa Mais Educação em uma escola do campo, situada em uma comunidade tradicional de pesca da Cidade de Rio Grande (RS).

\section{Contexto da Pesquisa: Escola do Campo}

A Escola Municipal de Ensino Fundamental Cristóvão Pereira de Abreu, a qual constitui o campo empírico desta pesquisa, tem o seu decreto de criação datado em 03/06/1942. Está localizada na Zona Rural, mais especificamente na Ilha da Torotama, a uma distância de aproximadamente sessenta quilômetros da sede Secretaria de Município da Educação (SMEd). Dedica-se, ao longo dos anos, a formação e a integração da comunidade, através de diversas atividades curriculares e extra-curriculares. Situada às margens da Laguna dos Patos, com acesso fluvial e terrestre, em uma comunidade cuja principal atividade econômica é a pesca artesanal. A escola atende aproximadamente cento e vinte alunos em dois turnos (manhã e tarde), oferecendo Educação Infantil, Anos Inicias e Finais do ensino fundamental. Com um quadro funcional de vinte docentes e seis funcionários, a mesma ainda conta com orientação educacional e sala de recursos multifuncional, atendendo diversos alunos com ou sem laudos médicos.

A escola tem como filosofia de trabalho "[...] que os educandos são agentes do processo educativo, instigados a questionar a realidade que o cerca e as relações que permeiam os espaços no qual estão inseridos [...]”. Para tal, através do diálogo, objetiva “[..] propiciar as novas descobertas, formando estudantes autônomos e com senso crítico. Assim, a educação estará voltada para a realidade dos sujeitos, tornando os saberes discutidos em sala de aula conexos as vivências cotidianas". (RIO GRANDE, 2015a, p.05).

O objetivo central da escola está em "[...] despertar a criticidade desses educandos, com aulas dinâmicas, dialógicas e, sobretudo oportunizando a esses sujeitos o direito de uma educação voltada às suas realidades” (RIO GRANDE, 2015a, p.4). Com isto, contribuirá na construção do conhecimento, pois, acredita que a educação se faz num processo dialético e contínuo. Está pautada na gestão democrática, “ [...] vislumbrando construir uma escola 
respeitando a identidade local, propiciando aos educandos um ensino público, gratuito e de qualidade" (RIO GRANDE, 2015b, p.3).

\subsection{A Nova Proposta Física e Pedagógica da Escola}

Para promover as mudanças necessárias, no ano de 2015, foram propostas alterações físicas e pedagógicas na estrutura da escola. Estas mudanças, foram pautadas no diálogo (FREIRE, 1996) com os diversos seguimentos da escola, bem como, avaliada periodicamente por todos os membros da comunidade escolar. O primeiro passo, foi promover uma nova disposição física dos espaços das salas de aula. Para isto, os espaços foram redistribuídos, formando "ambientes temáticos". Assim, a Educação Infantil até o $3^{\circ}$ (terceiro) ano, foram contemplados com ambientes que atendem as quatro áreas do conhecimento, divididos por cantos de aprendizagem, motivados pelo Pacto Nacional da Alfabetização na Idade Certa (PNAIC). Do $4^{\circ}$ ano ao $9^{\circ}$ ano, foram criados ambientes temáticos por área do conhecimento (linguagens e suas tecnologias; ciências humanas e suas tecnologias; ciências da natureza e suas tecnologias; matemática e suas tecnologias).

Com esta disposição, os alunos percorrem estes espaços de acordo com as disciplinas que compõem a área do conhecimento. Com isto, vamos de encontro à fórmula tradicional de organização dos espaços físicos da escola, a qual mantêm os alunos em turmas e salas fixas (ZABALA, 1998). Dentro destes ambientes, houve também uma preocupação em relação à disposição do mobiliário, a fim de, facilitar a aprendizagem e o trabalho coletivo entre os estudantes, pautada nos círculos de cultura (FREIRE, 2001; BRANDÃO, 2010). As salas de aula contam com recursos tecnológicos permanentes (computadores, projetores multimídia, rádio) e foram equipadas com mobiliário adequado (armários, estantes, etc), materiais escolares e pedagógicos específicos, bem como livros didáticos. Com isto, facilitou-se o acesso e a utilização destes recursos, no decorrer das aulas.

De nada adianta uma proposta de mudança física, sem uma renovação no fazer pedagógico e na postura dos educadores (SANTOMÉ, 1998, p. 131). Para isto, foi construida uma proposta de formação continuada para o corpo docente da escola. Dentre as atividades pensadas, estavam ações que possibilitarão o entendimento quanto a nova realidade, planejamento e construção de projetos, tipos de avaliações e atividades que venham a contribuir para a aprendizagem dos educandos. Também, discutiu-se as temáticas de interesse apontadas pelos professores: dificuldades na aprendizagem, questões relacionadas ao pertencimento, gênero e sexualidade, avaliação e planejamento escolar. 
Outros fatores contemplados durante as discussões, foram a construção de estratégias para sanar os problemas apontados, pelo diagnóstico do Programa Dinheiro Direto na Escola (PDDE Interativo) e pelas melhorias nos índices das avaliações externas e internas da escola. Entre estes fatores mais alarmantes, estavam os índices de reprovação em algumas disciplinas e distorção entre idade e série.

Diante da mudança, foi necessário atualizar o Regimento Escolar e o Plano Político Pedagógico (PPP) da escola. Com isto, foram revistas algumas estratégias que possibilitem melhorias na aprendizagem dos estudantes, dentre elas: ampliar os atendimentos na sala de recurso; a construção de novos projetos escolares; busca por metodologias diferenciadas em sala de aula e a implementação do Programa Mais Educação.

\section{Programa Mais Educação no Contexto da Educação do Campo}

O Programa Mais Educação foi instituído através da Portaria Interministerial número 17/2007 e pelo Decreto $n^{\circ} 7.083$, de 27 de janeiro de 2010, com intuito de integrar as ações do Plano de Desenvolvimento da Educação (PDE), como uma estratégia do Governo para o incentivo à ampliação do tempo na escola juntamente com a organização curricular, na perspectiva da Educação Integral (BRASIL, 2017).

Com isto, podemos dizer que a educação integral dispõe-se no cenário educacional como objetivo a ser alcançado pelas políticas públicas de educação em nível nacional. Como iniciativa política, é retomada a necessidade de intensificar o dialogo sobre a educação integral, pois, dela emergem "questões de cunho filosófico, [...] reflexões sociológicas, político-pedagógicas e administrativas" (CAVALIERE, 2002, p. 07). Desta maneira, faz-se necessário o estudo aprofundado, o qual promova uma série de argumentos que venham à somar nestes debates.

Podemos definir, então, o Programa Mais Educação, como uma ação entre as políticas públicas educacionais e sociais, que vem a contribuir, tanto para a diminuição das desigualdades educacionais, quanto para a valorização das diversas culturas. Conforme o Programa, fazem parte desta ação, o Ministério da Educação, o Ministério do Desenvolvimento Social e Combate à Fome, o Ministério da Ciência e Tecnologia, o Ministério do Esporte, o Ministério do Meio Ambiente, o Ministério da Cultura, o Ministério da Defesa e a Controladoria Geral da União (BRASIL, 2017).

É de suma importância refletir sobre o papel da escola na sociedade, visto que, ela se destina à promoção do homem, enquanto sujeito. Nisto, Freire (2000) nos chama a atenção para a necessidade de uma proposta político pedagógica alicerçada a uma criticidade, capaz 
de despertar no educando, o pensamento critico sobre a realidade social, histórica e política. $\mathrm{O}$ autor ainda destaca que, o educador deve ser aquele que "ensina os conteúdos de sua disciplina com rigor e com rigor cobra a produção dos educandos, mas não esconde a sua opção política na neutralidade impossível de seu que-fazer” (FREIRE, 2000, p.44), numa perspectiva de que não existe neutralidade na escola.

Conforme o Decreto n ${ }^{\circ} 7.083 / 2010$, os princípios da Educação Integral, são traduzidos pela compreensão do direito de aprender, como inerente ao direito à vida, à saúde, à liberdade, ao respeito, à dignidade e à convivência familiar e comunitária e, como condição para o próprio desenvolvimento de uma sociedade republicana e democrática. A partir disto, torna-se incontestável o papel fundamental da educação no que tange às condições necessárias para um sujeito se desenvolver de forma plena.

A Educação Integral faz-se presente na legislação educacional brasileira e, pode ser percebida em nossa Constituição Federal, nos artigos 205, 206 e 227; no Estatuto da Criança e do Adolescente (Lei no 9089/1990); na Lei de Diretrizes e Bases (Lei no 9394/1996), nos artigos 34 e 87; no Plano Nacional de Educação (Lei no 10.179/01) e no Fundo Nacional de Manutenção e Desenvolvimento do Ensino Básico e de Valorização do Magistério (Lei no 11.494/2007), (BRASIL, 2017).

Por sua vez, a Lei no 10.172, de 9 de janeiro de 2001, que instituiu o Plano Nacional de Educação (PNE), valoriza e compreende a Educação Integral como possibilidade de formação integral do indivíduo. O PNE, também apresenta como sua meta, a ampliação de forma progressiva da jornada escolar para um período de, pelo menos, sete horas diárias; além de promover a participação das comunidades nas gestões das escolas, visando incentivar o fortalecimento e a instituição de Conselhos Escolares.

A Lei no 11.494, de 20 de junho de 2007, que instituiu o FUNDEB, determina e regulamenta a Educação Básica em tempo integral e os Anos Iniciais e Finais do Ensino Fundamental (art.10, § 3o), o que indica que a legislação decorrente deverá normatizar esta modalidade de educação. Sendo assim, o decreto no 6.253/07, ao assumir o que foi estabelecido pelo PNE, definiu que considera-se "Educação Básica em tempo integral a jornada escolar com duração igual ou superior a sete horas diárias, durante todo o período letivo, compreendendo o tempo total que um mesmo estudante permanece na escola ou em atividades escolares" (art. 4o) (BRASIL, 2017). O Plano de Desenvolvimento da Educação prevê, que a formação do estudante seja feita além dos muros da escola, com a participação da família e de toda a comunidade.

A partir disto, o Programa Mais Educação segue as seguintes orientações: 
I. Contemplar a ampliação do tempo e do espaço educativo de suas redes e escolas, pautada pela noção de formação integral e emancipadora;

II. Promover a articulação, em âmbito local, entre as diversas políticas públicas que compõem

o Programa e outras que atendam às mesmas finalidades;

III. Integrar as atividades ao projeto político-pedagógico das redes de ensino e escolas participantes;

IV. Promover, em parceria com os Ministérios e Secretarias Federais participantes, a capacitação de gestores locais;

V. Contribuir para a formação e o protagonismo de crianças, adolescentes e jovens;

VI. Fomentar a participação das famílias e comunidades nas atividades desenvolvidas, bem como da sociedade civil, de organizações não governamentais e esfera privada;

VII. Fomentar a geração de conhecimentos e tecnologias sociais, inclusive por meio de parceria com universidades, centros de estudos e pesquisas, dentre outros;

VIII. Desenvolver metodologias de planejamento das ações, que permitam a focalização da ação do Poder Público em territórios mais vulneráveis; e

IX. Estimular a cooperação entre União, Estados, Distrito Federal e Municípios.

\subsection{Algumas Orientações para Implantação do Programa nas Escolas do Campo}

Levado em consideração a expansão do Programa Mais Educação em todo o Brasil, é necessária a definição de estratégias que venham a contribuir para a oferta de uma educação de qualidade, que seja compatível com o modo de viver, pensar e produzir dos sujeitos identificados com o campo. Caldart (2003), nos chama a atenção para a importância de trazer a escola para a realidade do campo

Uma educação que afirme o campo como o lugar onde vivem sujeitos de direitos, com diferentes dinâmicas de trabalho, de cultura, de relações sociais, e não apenas como um espaço que meramente reproduz os valores do desenvolvimento urbano. (p.64)

Sendo assim, as atividades do Programa Mais Educação, dentro desta proposta, não podem descaracterizar a realidade do campo e, as concepções pedagógicas deverão considerar a realidade dos locais, suas especificidades ambientais e étnicas, devendo alicerçar seus eixos nas categorias "terra, cultura e trabalho".

Os planos de atendimento deverão ser definidos de acordo com o projeto político pedagógico das unidades escolares e, desenvolvidos por meio de atividades, dentro e fora do 
ambiente escolar, ampliando o tempo, os espaços e as oportunidades educativas, na perspectiva da educação integral do estudante.

O Programa Mais Educação oferta para as escolas do campo os seguintes macrocampos: Acompanhamento Pedagógico; Agroecologia; Iniciação Científica; Educação em Direitos Humanos; Cultura, Artes e Educação Patrimonial; Esporte e Lazer; e Memória e História das Comunidades Tradicionais.

\subsection{Mais Educação no Contexto da E.M.E.F. Cristóvão Pereira de Abreu}

Entre estas atividades, muitos foram os projetos e programas executados na escola, os quais visavam contribuir com a melhoria no fazer pedagógico e na aprendizagem dos estudantes. O Programa Mais Educação, que é desenvolvido na escola desde o ano de 2014, inicialmente aderiu aos macrocampos: acompanhamento pedagógico (o qual era obrigatório); Cultura, Artes e Educação Patrimonial; Memória e História das Comunidades Tradicionais. Contando com cinco oficineiros, sendo dois atuantes no primeiro macrocampo e três atuando em conjunto nos demais macrocampos.

Para o acompanhamento pedagógico, são desenvolvidas aulas de apoio em parceria com os professores da escola, desde a Educação Infantil até o nono ano do Ensino Fundamental. Como o foco em Alfabetização e Letramento, Português e Matemática, estas aulas, visam sanar as dúvidas por parte do alunos e auxiliar no seu desenvolvimento e de sua aprendizagem. .

As atividades do Mais Educação também abrangem as artes e a cultura da comunidade. Para isto, são desenvolvidas atividades que buscam resgatar e valorizar a cultura popular do povo, da Ilha da Torotama. No campo das artes, com o auxílio dos professores e oficineiros, são desenvolvidas oficinas e mostras, bem como, peças teatrais que são levadas à eventos promovidos pela Secretaria de Município da Educação. Estas ações, compõem o calendário escolar de atividades.

\section{Conclusões}

No que diz respeito aos objetivos do Programa Mais Educação em relação à promoção e ampliação de tempos, espaços e oportunidades educativas, podemos concluir que, no contexto da Escola Cristóvão Pereira de Abreu, as ações propostas e desenvolvidas estão sendo exitosas. É comprovado que houve o aumento no índice de rendimento escolar dos alunos, chegando a quase $95 \%$ (noventa e cinco por cento) de aprovação. 
Cabe ainda, destacar a criação da Banda Marcial Cristóvão Pereira de Abreu. Com o financiamento do Programa Mais Educação, as atividades que fazem parte da banda, tais como: oficina de música, percussão, coreografia e partituras, realizadas em turno inverso, propiciam aos estudantes uma ampliação do seu tempo de permanência, dentro do espaço escolar.

Todas estas estratégias resultam em um importante espaço de integração entre alunos, professores e comunidade. As dinâmicas de integração, como banda e teatro, auxiliaram também no desenvolvimento interpessoal dos estudantes, diminuindo a sua timidez, motivando-os a participar mais ativamente das atividades escolares.

\section{Referências}

BRANDÃO, Carlos Rodrigues. Educação Popular na Escola Cidadã. Vozes, Petrópolis, 2000.

BRANDÃO, Carlos R. Círculos de cultura. In. STRECK, Danilo; REDIN, Euclides; ZITKOSKI, Jaime J. (orgs.). Dicionário Paulo Freire. 2a ed. Belo Horizonte: Autêntica Editora, 2010.

BRASIL. Manual Operacional de Educação Integral. Disponível em: <http://portal.mec.gov.br/>. Acesso em 18 de outubro de 2017.

CALDART, Roseli Salete. A Escola do Campo em Movimento. Currículo sem Fronteiras, v.3, n.1, pp.60-81, Jan/Jun 2003.

CAVALIERE, Ana Maria. Educação Integral: Uma nova identidade para a escola Brasileira. Revista Educação e Sociologia, Campinas, Vol. 23, n. 81, dezembro. 2002, p. 247270.

FREIRE, Paulo. Pedagogia da autonomia: Saberes necessários à prática educativa/ São Paulo: Paz e Terra, 1996 (coleção leitura).

FREIRE, Paulo. Pedagogia da indignação: cartas pedagógicas a outros escritos. São Paulo: UNESP, 2000.

Ministério da Educação, Programa Mais Educação. Disponível em:

$<$ http://portal.mec.gov.br/programa-mais-educacao/apresentacao〉. Acesso em 18 de outubro de 2017.

PALUDO, Conceição. Educação Popular e Educação (Popular) do Campo. In: MIRANDA, Sônia Guariza; SCHWENDLER, Sonia Fátima (Org.). Educação do Campo em movimento: teoria e prática cotidiana. v. 1. Curitiba: Ed. UFPR, 2001. 
RIO GRANDE. Plano Político Pedagógico Escola Municipal de Ensino Fundamental Cristovão Pereira de Abreu. Rio Grande: Escola Municipal de Ensino Fundamental Cristovão Pereira de Abreu, 2015.

RIO GRANDE. Regimento Escolar da Escola Municipal de Ensino Fundamental Cristovão Pereira de Abreu. Rio Grande: Escola Municipal de Ensino Fundamental Cristovão Pereira de Abreu, 2015.

SANTOMÉ, Jurjo Torres. Globalização e Interdisciplinaridade: o currículo integrado. Porto Alegre: Arte Médicas Sul, 1998.

ZABALA, Antoni. A prática Educativa: como ensinar. Porto Alegre: Artmed, 1998. 